$$
\begin{aligned}
& \text { SF } 808 \\
& \text { P3 }
\end{aligned}
$$




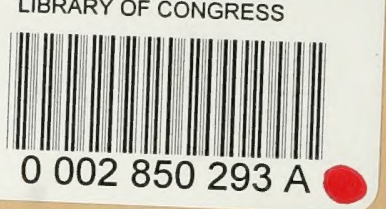

Hollinger Corp. pH 8.5 

TUBERCULOSIS.

\author{
BY \\ LEONARD PEARSON, B.S., V.M.D., \\ AND \\ S. H. GILLILAND, V.M.D., M.D.
}

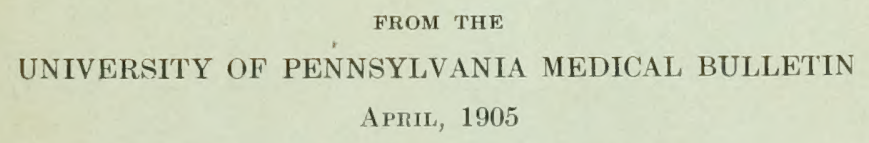




$$
\begin{aligned}
& S F_{808} \\
& P_{3}
\end{aligned}
$$

\section{IN EXCHANGE BOS, ANTH. \\ Mr 3 '06}

$$
\because \vdots \vdots
$$


Reprinted from the University of Pennsylvania Medical Bulletin, April, 1905.

\title{
THE EFFECT OF TUBERCULOSIS VACCINATION UPON CATTLE INFECTED WITH TUBERCULOSIS.'
}

\author{
By Leonard Pearson, B.S., V.M.D., \\ State Veterinarian of Pennsylvania,
}

AND

S. H. Gilliland, V.M.D., M.D.,

Bacteriologist of the State Livestock Sanitary Board of Pennsylvania.

DURING recent years a large amount of work has been done by Koch, Trudeau, de Schweinitz, von Behring, Maragliano, Fraenkel, and others, for the purpose of discovering and developing a specific treatment for tuberculosis. This work has taken various directions, and has included experiments wherein the toxins of tubercle bacilli have been administered and experiments wherein antitoxins found in the blood of animals that have been treated with toxins have been used. Toxins of various kinds have been employed; from the original and new tuberculin of Koch to the toxalbumin, the watery tuberculin, the tubercle bacilli deprived of fat of Maragliano, and bacillary pulp.

The antitoxins that have been used have been developed as a result of the injection of the various toxins mentioned above, and also living tubercle bacilli of low virulence.

The reports of the therapeutic experiments made upon infected animals with tuberculosis toxins and antitoxins

1 Read before the Pathological Society of Philadelphia, Dec. 22, 1904. 
are numerous, but cannot be regarded as convincing. Most of these experiments have been made upon rabbits and guinea-pigs. Neither rabbits nor guinea-pigs are altogether satisfactory for experiments of this kind; the former because of their comparative immunity to tubercle bacilli of the human type, the latter on account of their excessive vulnerability to inoculation tuberculosis of either of the mammalian types. Enough work has been done to denote that the progress of a tuberculous infection may be controlled in some degree by specific means. It is important that these various methods shall be compared and measured both quantitatively and qualitatively. There is here a large and important field of labor for the critical experimentalist.

Among the means that have been proposed for controlling the spread of tuberculosis among cattle is vaccination, or the inoculation of animals with living cultures of tubercle bacilli of low virulence for the animals upon which they are inoculated. This method of producing artificial immunity has been the subject of considerable study both in this country and in Europe, and has been reported upon to this Society by the writers of this paper.

In connection with some tuberculosis vaccination experiments made by the writers, the opportunity occurred to test the effect of vaccination upon some young cattle already infected with tuberculosis. As this treatment appears to have had a decided effect upon the course of the disease in the infected animals treated, it is considered that our observations should be placed upon record, especially since the work covered nearly two years, long enough to show definite results, and is the first of the sort of which we have knowledge.

In testing with tuberculin a large herd of shorthorn and grade shorthorn eattle in December, 1902, that was known to have been infected with tuberculosis for a number of years, it was found that practically all of the members of the herd responded affirmatively to the test. Among the animals 
so responding were twelve calves from six to eight months old. As these calves had mingled rather freely with the members of the herd, and as they had been reared on the milk of extensively tuberculous cows, it was not surprising to find that they responded to the tuberculin test. These twelve calves were obtained for use in this experiment. They were shipped to Philadelphia and were placed in a temporary building on the grounds of the veterinary school, where they were kept apart from other cattle.

The twelve calves were again tested with tuberculin February 2, 3, 1903. All responded to this test. They were then weighed and divided into two lots, of six each, as nearly equal as possible in respect to age, size, weight, and condition. One of these lots was subdivided into two groups of three each.

The three calves of one of the sub-groups were giver seven intravenous injections of a standard suspension ${ }^{1}$ in water of tubercle bacilli of human type (culture M). The dosage began at 1 c.c. and was increased to 6 c.c.. The intervals between injections were from six to twenty days, and the period covered was from February 9 to May 1, 1903 , as is shown by the protocols. These same calves received another and final intravenous injection of 5 c.c. of a standard suspension of living tubercle bacilli (culture M) about a year later, March 29, 1904.

The three calves of the second sub-group were given subcutaneous injections of tuberculin at intervals of from two to ten days. The injections of tuberculin were repeated until the hypersensitiveness of the animal to tuberculin had disappeared, after which the calves received an intravenous:

1 By a standard suspension is here meant a suspension of tubercle bacilli in water, in such quantity as to give an opacity equal to that of a twenty-four-hour culture of typhoid bacilli in bouillon; 1 c.c. of such a suspension is estimated to contain the equivalent of 0.0013 gram of tubercle bacilli dried ten days in a desiccating chamber over calcium chloride. 
injection of a suspension of tubercle bacilli (culture M) in water. Following each intravenous injection of living tubercle bacilli, the animal was again given tuberculin a number of times until its hypersensitiveness to tuberculin again disappeared. The procedure in these cases in respect to the order of the injections of tuberculin bacilli was as follows: Two subcutaneous injections of tuberculin, an intravenous injection of tubercle bacilli, six injections of tuberculin, an injection of tubercle bacilli, six injections of tuberculin, an injection of tubercle bacilli, three injections of tuberculin. The period of treatment extended from February 9 to April 30, 1903, inclusive; the exact times of administration and the doses are shown by the protocols. The calves of this group, as of the first group described, were given an intravenous injection of 5 c.c. of standard suspension of living tubercle bacilli (culture M) March 29, 1904. Following this, tuberculin was administered five times at intervals of three or four days.

The remaining six calves were given no treatment whatever, but were, at all times, kept with the six calves under treatment; so that all of the twelve calves in this experiment were subjected to the same conditions of life and subsisted upon the same kind and quantity of food.

All of the calves were kept in a stable until May 29, 1903, when they were placed upon pasture, which became very scanty during the latter part of the season. During the winter of 1903-04 the cattle were fed mixed hay, corn fodder, and a grain mixture of bran and corn meal. Only a little grain was fed. About the middle of May, 1904, the cattle (now about two years old) were again placed on pasture, where they remained until they were killed at the close of the experiment.

Two cattle, both controls, died; the first one May 5, 1903; the second September 13, 1904; two, one control and one treated, were killed April 4, 1904, and the rest were killed in September, 1904. 
When the cattle in this experiment died or were killed they were submitted to careful post-mortem examination. Material was stained for examination for tubercle bacilli and guinea-pigs were inoculated from the lesions of some of them. Histological examinations of the lesions were made by Dr. C. Y. White, to whom we are greatly indebted for reports upon his examinations.

The treatments and post-mortems are summarized in the following protocols:

First Group. Three calves that received intravenous injections of tubercle bacilli alone.

FIG. 1.-Red Bull (16,013).

1902. December 19. 0.1 c.c. tuberculin; reaction.

1903. February

2. 0.8 c.c.

to $106.2^{\circ} \mathrm{F}$.

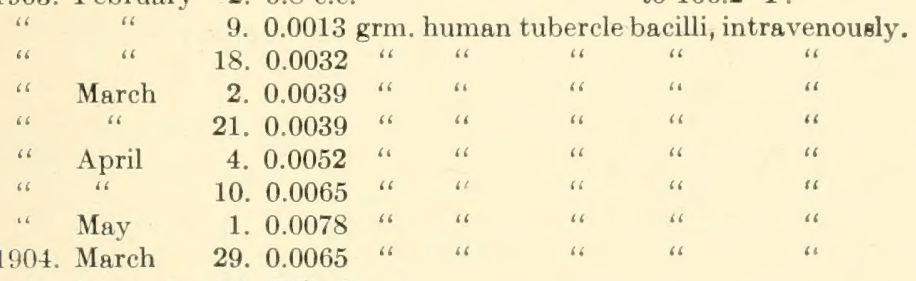

“ September 15. Killed.

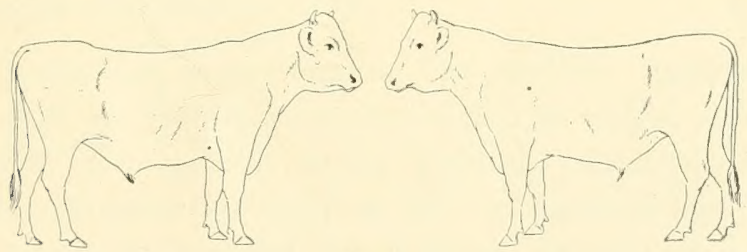

Right lung.

Fi'1. 1 .

Left bronchial gland.

Necropsy. Weight 643 pounds; fair condition. The lesions of tuberculosis found in this animal were as follows: At the lower border of the middle lobe of the right lung was a slightly depressed area about one-half inch in diameter containing a collection of thick yellow pus filling a cavity the size of a large pea. The walls of this cavity are oneeighth of an inch thick, white, and of firm, dense texture. In one of the left peribronchial glands there is a caseocal- 
careous nodule about the size of a pea and having the appearance of a wholly closed process. Guinea-pigs inoculated from the lesion in the lung became tuberculous.

\section{FIG. 2,-Red-and-white Bull $(16,017)$.}

1902. December 19. 0.1 c.c. tuberculin; reaction.

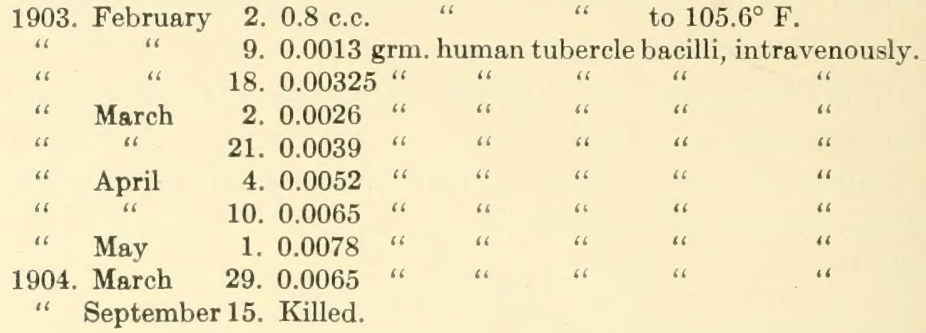
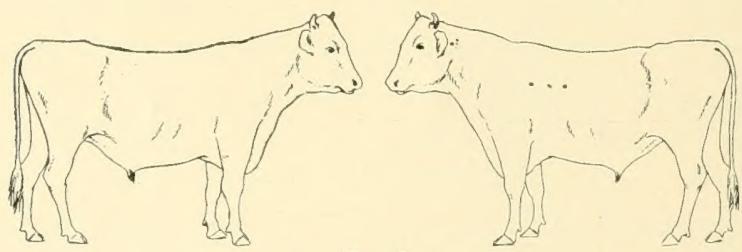

Fig. 2.

Postpharyngeal gland.

Left bronchial gland.

Mediastinal gland, middle and posterior.

Necropsy. Weight 467 pounds; good condition. The following lesions of tuberculosis were found: In one of the left peribronchial glands a yellow, caseous area one-tenth of an inch in diameter. In the posterior mediastinal gland there is an area the size of a pea, yellow in color and quite calcareous, surrounded by a white, dense capsule. In the middle mediastinal gland there is a similar area, though much smaller, being but one-twelfth of an inch in diameter. In one of the postpharyngeal glands there is a caseocalcareous area one-half of an inch in diameter, surrounded by an unusually thick, dense, white, fibrous wall. The caseous collection contains many calcareous grains. There are also in this gland three other similar areas, much smaller, about one-eighth of an inch in diameter, and each is surrounded 
by a dense capsule. In addition to this evidence of tuberculosis it was olserved that both lungs, although generally well inflated, were heary, soggy, somewhat leathery and without elasticity. There were some small areas where the tissues were contracted and dense. Histologically these areas show numerous dense bands of comnective tissue. The bloodvessels are very much thickened. In limited areas some of the smaller ones are almost obliterated. Some of the smaller sublobules show the lung tissue to be collapsed or organized. The peribronchial lymphatic tissue is increased and the pleura is thickened. There is no caseation or evidence of a tubercular process excepting as above noted. Guinea-pigs inoculated with the caseocalcareous material from the thoroughly encapsulated lesions in the postpharyngeal glands became tuberculous.

Fig. 3.-Roan Heifer $(16,021)$.

1902. December 19.0 .1 c.c. tukerculin; reaction.

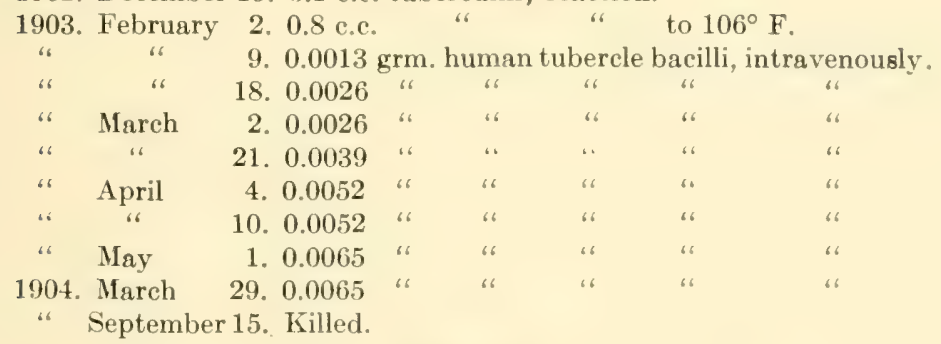

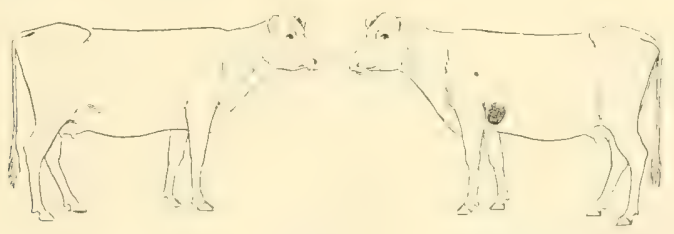

FIG. 3.

Left lung.

Left bronchial gland.

Necropsy. Weight 465 pounds; good condition. The evidence of tuberculosis here consists in a very dense condition of the lower half of the posterior flap of the anterior lobe of the left lung, which is attached to the posterior lobe and 
to the pericardium and the diaphragm. This dense mass consists of a very thick wall of fibrous tissue surrounding a sequestrum of lung tissue, about one and a half inches in its anteroposterior and two and a half inches in its vertical diameter. Above this mass the lung tissue of the anterior lobe contains an excessive quantity of fibrous tissue appearing as white bands between the lobules. These bands are quite firm and are from one-eighth to one-quarter of an inch wide. The parenchyma surrounded by these bands is studded with fine dots and lines of white, consisting of fibrous tissue. Above this sclerotic zone the lung tissue is elastic and pink. There are nowhere nodules or caseous areas, excepting in one of the left peribronchial glands which contains a caseocalcareous nodule the size of a pea.

There is reason to believe that in this animal there has been an extensive area of tuberculous tissue in the lower portion of the anterior lobe of the left lung. This area appears to have become encysted and the lung tissue above to have been the seat of numerous small tubercles which were transformed into sear tissue and appear now very much hardened and contracted.

SECOND GROUP. Three calves which received intravenous injections of tubercle bacilli alternating with repeated subcutaneous injections of tuberculin.

FIG. 4.--Red-and-white Heifer $(16,015)$.

1902. December 19. 0.1 c.c. tuberculin; reaction.

$\begin{array}{cc}\text { 1903. February } \\ \text { " } \\ \text { " } \\ \text { " } & \text { " } \\ \text { " } & \text { " } \\ \text { " } & \text { March } \\ \text { " } & \text { " } \\ \text { " } & \text { " } \\ \text { " } & \text { " }\end{array}$

2. 0.8 c.c.

to $105.8^{\circ} \mathrm{F}$.

9. $1.0 \mathrm{c.c}$.

"6
to $102.8^{\circ} \mathrm{F}$.

15. 1.5 c.c. to $103.0^{\circ} \mathrm{F}$.

18. $0.0026 \mathrm{grm}$. human tubercle bacilli, intravenously.

22. 1.0 c.c. tuberculin; reaction to $103.0^{\circ} \mathrm{F}$.

24. 1.5 c.c.

" to $102.6^{\circ} \mathrm{F}$.

4. 2.0 c.c.

" to $104.6^{\circ} \mathrm{F}$.

6. 2.5 c.c.

"to $102.8^{\circ} \mathrm{F}$.

11. 3.0 c.c.

" to $103.0^{\circ} \mathrm{F}$.

14. 3.5 c.c.

" to $103.0^{\circ} \mathrm{F}$.

21. $0.0039 \mathrm{grm}$. human tubercle bacilli, intravenously.

27. 1.0 c.c. tuberculin ; reaction to $103.2^{\circ} \mathrm{F}$.

29. 1.5 c.c.

to $103.0^{\circ} \mathrm{F}$. 
1903. April

$\begin{array}{ll}66 & 66 \\ 66 & 66 \\ 16 & 46 \\ 66 & 16 \\ 16 & 66 \\ 66 & 66\end{array}$

1904. March

"April

$\begin{array}{ll}" 6 & " 6 \\ " 6 & " \\ " 6 & 4 \\ " 6 & 6\end{array}$

5. 2.0 c.c. tuberculin ; reaction to $102.6^{\circ} \mathrm{F}$.

8. 2.5 c.c. " " " $"$ to $102.2^{\circ} \mathrm{F}$.

10. 3.0 c.c. " " " to $104.0^{\circ} \mathrm{F}$.

16.3 .5 c.c. " " to $103.6^{\circ} \mathrm{F}$.

18. $0.0052 \mathrm{grm}$. human tubercle bacilli, intravenously.

23. 0.5 c.c. tuberculin; reaction to $104.6^{\circ} \mathrm{F}$.

27. 1.0 c.c. " " to $102.6^{\circ} \mathrm{F}$.

30. 2.0 c.c. " " to $103.6^{\circ} \mathrm{F}$.

29. $0.0065 \mathrm{grm}$. human tubercle bacilli, intravenously.

September 15. Killed.

1. 1.0 c.c. tuberculin; reaction to $102.8^{\circ} \mathrm{F}$.

3. 2.0 c.c. " " " to $103.3^{\circ} \mathrm{F}$.

8. 3.0 c.c. " " " to $102.4^{\circ} \mathrm{F}$,

11. 4.0 c.c. " " $" 102.9^{\circ} \mathrm{F}$.

15. 5.0 c.c. " " to $103.8^{\circ} \mathrm{F}$.

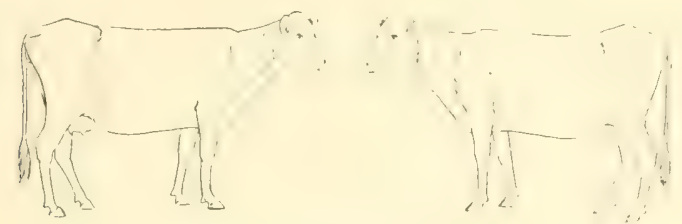

Fra. 4.

Left bronchial gland.

Necropsy. Weight 566 pounds; good condition. The only evidence of tuberculosis in this animal is a calcareous nodule one-eighth of an inch in diameter situated in one of the left peribronchial glands. This nodule is sharply differentiated from the surrounding adjacent, quite normal glandular tissue, and has the appearance of a completely closed process. Guinea-pigs inoculated with an emulsion of this nodule developed tuberculosis.

\section{FIG. 5.-Red-and-white Heifer (16,019).}

1902. December 19. 0.1 c.c. tuberculin; reaction.

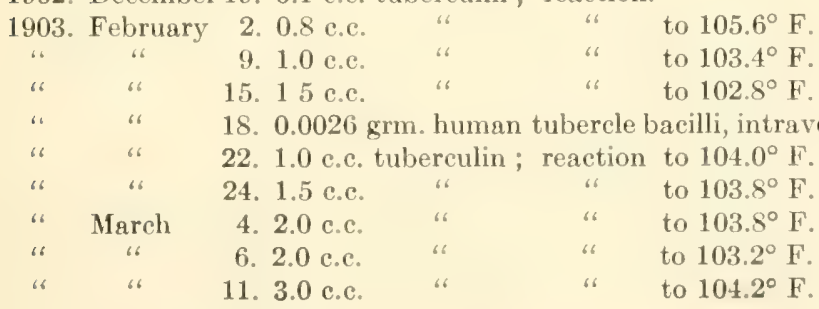

Pearson and Gillitand 
1903. March

" " "

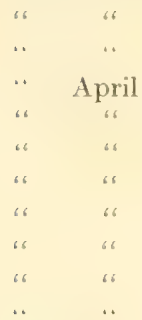

1904. March

"April

$\begin{array}{ll}" \text { " } & \text { " } \\ " 6 & 6 \\ " 6 & 6\end{array}$

14. 3.5 c.c. tuberculin; reaction to $103.8^{\circ} \mathrm{F}$.

21. $0.0039 \mathrm{grm}$. human tubercle bacilli, intravenously.

27. 1.0 c.c. tuberculin; reaction to $104.6^{\circ} \mathrm{F}$.

29. 1.5 c.e.

5. 2.0 c.c.

8. 2.5 c.c.

10. 3.0 c.c.

16. 3.5 c.c.

18. $0.0052 \mathrm{grm}$. human tubercle bacilli, intravenously.

23. 0.5 c.c. tuberculin; reaction to $102.8^{\circ} \mathrm{F}$.

27. 1.0 c.c. " " " to $102.4^{\circ} \mathrm{F}$.
30.2 .0 ('.e.
“ to $103.8^{\circ} \mathrm{F}$.

29. $0.0065 \mathrm{grm}$. human tubercle bacilli, intravenously.

1. 1.0 c.c. tuberculin; reaction to $102.9^{\circ} \mathrm{F}$.

4. 2.0 c.c. " " " to $103.0^{\circ} \mathrm{F}$.

8.3 .0 c.e. " " " to $103.0^{\circ} \mathrm{F}$.

11. 4.0 c.c. " " " to $103.8^{\circ} \mathrm{F}$.

15. 5.0 e.e. " " to $102.4^{\circ} \mathrm{F}$,

"September 15. Killed.

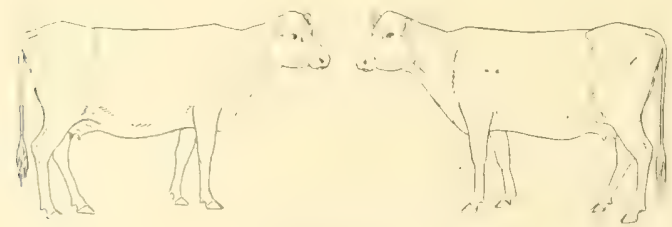

FIG. 5.

Left bronchial gland.

Neropsy. Weight 5.50 pounds; good condition. One of the left peribronchial glands contained two nodules, each about one-tenth of an inch in diameter. Both are distinctly calcareons and are sharply differentiated from the immediately adjacent, quite normal gland tissue.

'The right lung is rather dense and leathery and contains some collapserl areas. In such a collapsed area there is found an infiltration of round cells surroumling the bronchial walls. 'The lymphatic nodes in the same region are greatly' increased. The alveoli are oerlematous and in some places the exudate has undergone organization.

There is no evidence of caseation or of tuberculosis in the lungs or elsewhere, excepting as noted in the left peribronchial gland. 
FiG. 6.-Red Heifer (16,022).

1902. December 19. 0.1 c.c. tuberculin; reaction.

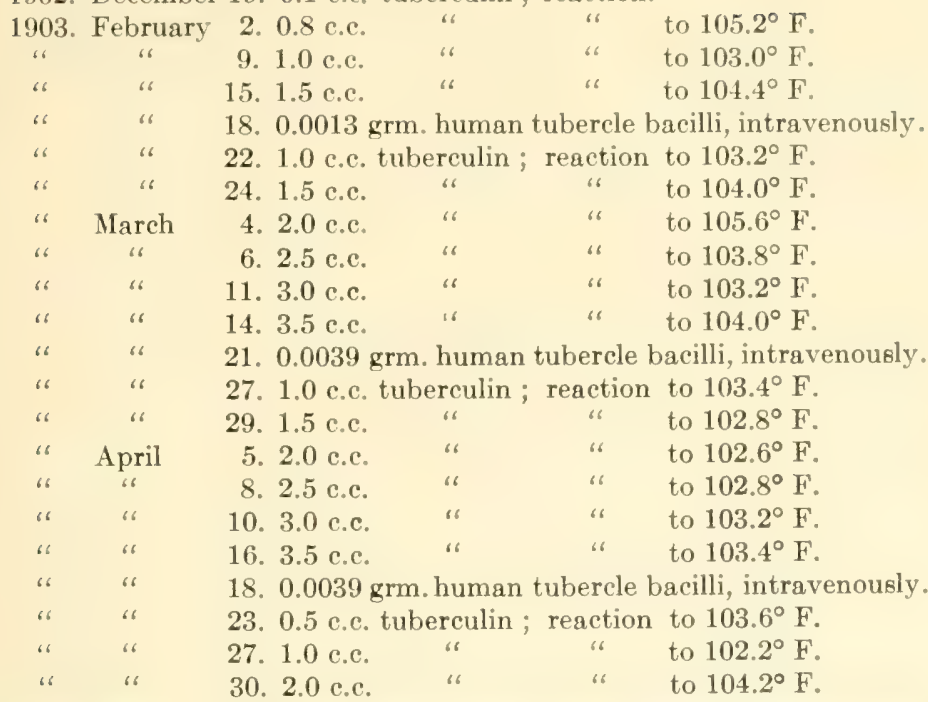

1904. March 29. $0.0065 \mathrm{grm}$. human tubercle bacilli, intravenously.

"April 1. 1.0 c.c. tuberculin; reaction to $103.0^{\circ} \mathrm{F}$.

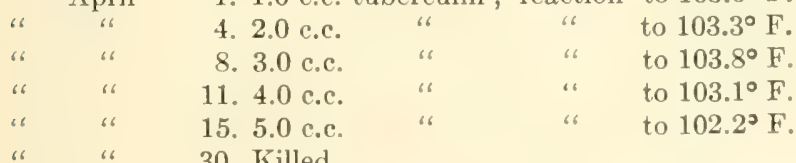

30. Killed.

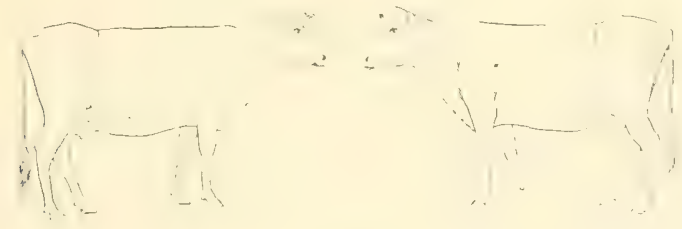

FIG. 6.

Left bronchial gland.

Necropsy. Weight 421 pounds; unthrifty condition. The only distinct evidence of tuberculosis in this animal is a calcareous nodule the size of a pea in the left bronchial gland. The pleura and peritoneum were more or less opaque and showed films or flakes of fibrin partly or wholly organ- 
ized and in some places evidently of considerable age. Guinea-pigs inoculated from the calcareous nodule in the bronchial gland became tuberculous.

It is evident that this animal had suffered with a widespread inflammation of the serous membranes from which it had practically recovered. Such a diffuse inflammation of the serous membranes of both visceral cavities occurs in tuberculosis of cattle of the type of pearl disease. But in this case there were no tubercles or evidence of tuberculosis. One must consider the possibility that in this animal there was a healed, fresh tuberculosis of the pleura and peritoneum.

ThIRD Group. Six calves which received no treatment and were kept as controls for the purpose of comparison.

FIG. 7.-Red-and-white Bull (16,014).

1902. December 19. 0.1 c.c. tuberculin; reaction.

1903. February 2. 0.8 c.c. " " $105.6^{\circ} \mathrm{F}$.

"May 4. Died.

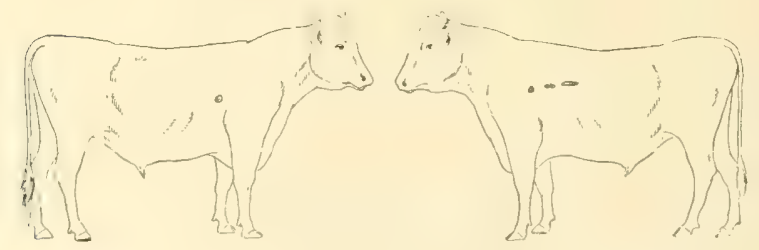

FIG. 7.

Right bronchial gland.

Left bronchial gland. Mediastinal glands.

Necropsy. Weight 430 pounds. This bull died suddenly, apparently of acute indigestion. The only evidence of tuberculosis in this animal consisted in the presence of several caseous nodules in both bronchial and in the mediastinal lymphatic glands. 
FIG. 8.-Red-and-white Heifer (16,016.

1902. December 19. 0.1 c.c. tuberculin ; reaction.

1903. February 2. 0.8 c.c. " " to $106.0^{\circ} \mathrm{F}$.

1904. September 17. Killed.
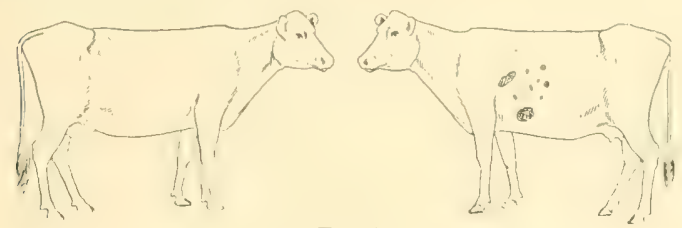

FIG. 8 .

Left lung.

Mediastinal gland.

Necropsy. Weight 578 pounds; poor condition. In the left lung at the bottom of the posterior lobe there is an area containing numerous tubercles, some of which have undergone caseation. Two similar areas are found in the tip of the lung. The surrounding lung tissue is red and dense and is infiltrated with small gray tubercles of pinhead size, some of which have cheesy centres. The posterior mediastinal gland is five inches long and two inches in diameter. This gland is filled with dense nodules, most of which have undergone caseation, and some of which contain calcareous deposits. Guinea-pigs inoculated with infiltrated lung tissue developed tuberculosis.

FIG. 9.-Red-and-white Heifer (16,018).

1902. December 19. 0.1 c.c. tuberculin ; reaction.

1903. February 2. 0.8 c.c. " " to $106.4^{\circ} \mathrm{F}$.

1904. September 19. Killed.

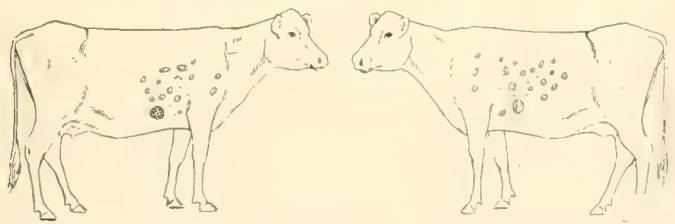

FIG. 9.

Right lung.

Left lung.

Bronebial glands.

Mediastinal glands. 
Necropsy. Weight 415 pounds; poor condition. Both the anterior and middle lobes of the right lung are attached to the chest wall; the anterior lobe is also attached to the pericardium. There are numerous tuberculous areas of all ages and up to one and a half inches in diameter scattered rather thickly through both lungs. Both bronchial and the mediastinal glands are enlarged and contain numerous caseous and caseocalcareous nodules.

FIG. 10.-Red-and-white Bull $(16,020)$.

1902. December 19. 0.1 c.c. tuberculin ; reaction.

1903. February 2. 0.8 c.c. " " to $105^{\circ} \mathrm{F}$.

1904. September 13. Died.

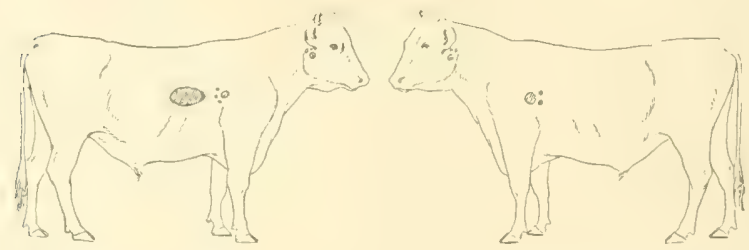

FIG. 10 .

Bronchial glands.

Mediastinal glands.

Postpharyngeal glands.

Postpharyngeal glands.

Bronchial glands.

Necropsy. Weight 480 pounds; fair condition. This bull was apparently quite healthy on the 12 th of September, and was found dead in the stable the next day. It was found that there was a great collection of gas in the paunch and this appears to have been the cause of death, through interference with respiration by pressure upon the diaphragm. The evidence of tuberculosis in this animal consisted in the presence of several caseous nodules in both bronchial glands; the posterior mediastinal gland is six inches long and quite thick. The entire structure of this gland has undergone degeneration. Both postpharyngeal lymphatic glands are slightly enlarged and contain caseous areas.

It is quite possible that in this case the enlarged mediastinal lymphatic gland was a contributing cause of death 
through pressing upon the oesophagus and tending to interfere with the regurgitation of gas.

FIG. 11.-Red-and-white Heifer $(16,023)$.

1902. December 19.0 .1 c.c. tuberculin ; reaction.

1903. February 2. 0.8 c.c. " " to $106.4^{\circ} \mathrm{F}$.

1904. April 30. Killed.

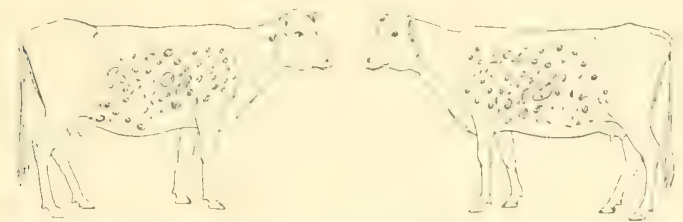

FIG. 11.

Postpharyngeal gland.

Left lung, etc.

Right lung.

Right pleura.

Bronchial glands.

Mediastinal glands,

Omentum.

Spleen.

Liver.

Necropsy. Weight 313 pounds; very poor condition. this heifer was killed because it was in such bad condition that it could not live long.

The costal pleure of both sides are coated with masses of round and flattened nodules occurring singly and in patches. The largest patch is nearly a foot in diameter and about two inches thick. Both lungs are covered with round and flattened nodules, some of which are closely attached to the pleura and some of which hang from the pleura singly and in clusters. There is a fringe around the borders of the lungs about two inches wide and rery thickly studded with hard nodules, the centres of which have undergone caseation. Both lungs contain a large number of caseous areas. The bronchial and mediastinal lymphatic glands are considerably enlarged and caseous. The postpharyngeal glands are in similar condition. The omentum, the walls of the stomachs, the abdominal walls, the spleen and liver 
are coated with nodular masses that are characteristic of pearl disease. There are numerous caseous areas in the substance of the liver. The bronchial lymphatic glands are enlarged to several times their natural size and are caseous.

This is a case of "pearl disease" in the most advanced form and of widest distribution.

FIG. 12.-Red-and-white Bull $(16,024)$.

1902. December 19. 0.1 c.c. tuberculin; reaction.

1903. February 2. 0.8 c.c. " " to $106^{\circ} \mathrm{F}$.

1904. September 17. Killed.

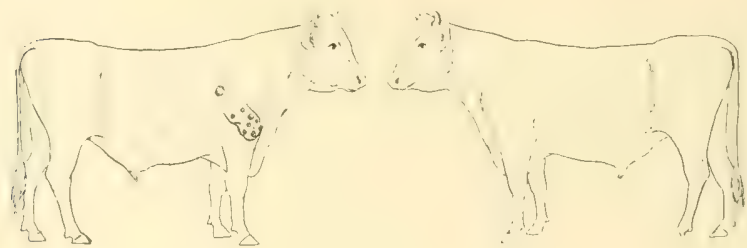

FIg. 12.

Right lung.

Right bronchial gland.

Necropsy. Weight $52 t$ pounds; good condition. The right bronchial gland is somewhat enlarged and contains a calcareous nodule. In the anterior lobe of the right lung there are numerous nodules containing pus. These are surrounded by firm, fibrous walls. The intervening lung tissue is collapsed.

The olservations here recorded show a decided difference between the lot of six young cattle that were treated and the six that were not treated. Since the two lots of animals were in all respects as nearly equal as possible at the beginning of the experiment, and since they were cared for all together and in precisely the same way, excepting in respect to specific treatment, it is but fair to conclude that the six treated animals were favorably influenced by the treatment. 
We believe that we have sufficient evidence to justify the statement that the treatment to which six of the animals were subjected had the effect not only of keeping in check the progress of the tuberculous process, but in causing a distinct and in some cases (Nos. 2, 3, and 6) a great retrogression of the lesions. In other words, the treatment had a distinct curative effect.

In all of the treated animals the lesions were quiescent and encapsulated. But they contained living tubercle bacilli. There is room for difference of opinion as to whether an animal or a person in which there is a tuberculous lesion containing living bacilli may be regarded as cured. If the lesion is wholly cut off by a thick fibrous wall from living tissue and if it is incapable of again becoming active, it would appear that a claim for a cure might fairly be entered. But how is one to know that activity may not be re-established? If there is resistance enough to cause the complete encapsulation of all tuberculous lesions in the body, it is evidence that a considerable degree of immunity had been developer. If the bacilli in the lesions are of such low virulence that they cannot infect an animal of the species of the one in which they are found, renewed activity is not to be expected. De Schweinitz found living tubercle bacilli in minute nodules in the lungs of a cow inoculated intravenously a year before with bacilli of human type that appear to have been incapable of producing progressive disease. Nodules may occur from intravenous injections of dead tubercle bacilli. Fraenkel and von Behring have found in lesions of tuberculosis of cattle tubercle bacilli that are not pathogenic for cattle.

Unfortunately, in these experiments, the virulence for cattle of the tubercle bacilli in the lesions in the treated animals was not determined.

These experiments which were made on a few young cattle in the earlier stage of tuberculosis do not justify conclusions or inferences as to the probable effect of similar treatment lon older and more extensively diseased animals. Experi- 
ments must be made on a larger and broader scale. We have at this time a number of animals under treatment which we hope will give us more knowledge on this subject. But we hold that the experiments that have been made show clearly that under such treatment as was given tuberculous" lesions do not extend; on the contrary, that they recede and that new implantations do not occur even upon prolonged contact with tuberculous herd mates. 



\section{LIBRARY OF CONGRESS}

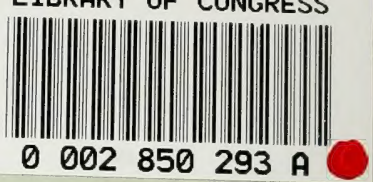




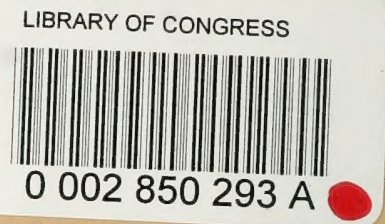

Hollinger Corp. pH 8.5 